\title{
INTERACTIVE REPAIR AMONG ENGLISH AS A LINGUA Franca Speakers in Academic SetTings
}

\begin{abstract}
The paper presents the results of research which studies the use of English as a lingua franca in spoken academic discourse interactions, providing a deeper insight into the interactional practices utilized in the process of achieving the communicative purpose(s) of international university seminars. Drawing on audio-recorded data collected from English-taught seminars at the University of Ostrava and using conversation analytic procedures, the research explores the character and functions of interactive repair and its role in increasing mutual understanding and preventing communication breakdown in lingua franca academic talk. The article discusses strategies of providing language support and/or feedback to one's communicative partners in negotiating both meaning and form of talk, and offers findings which portray ELF speakers as competent communicators adaptable to different sociopragmatic contexts.
\end{abstract}

Keywords

English as a lingua franca; academic talk; interactive repair; collaborative strategies; acceptability negotiation; conversation analysis

\section{Introduction}

The globalisation of English is a fait accompli in the current century, and scientific discoveries and knowledge can nowadays be spread thanks to a single global language, as many professionals from non-English speaking communities choose English as the unique and supreme scientific means of communication. Similarly, in the globalised academia, university lecturing has grown largely international thanks to extensive student and staff exchanges, joint development 
and implementation of new educational programmes. This involves increasing numbers of students and academic workers from diverse linguistic and cultural backgrounds becoming members of secondary discourse communities, which use English as the lingua franca (henceforth also ELF) in achieving their shared goals and communicative purposes. Consequently, they are challenged with the task of communicating successfully with each other, i.e. producing, receiving and responding to comprehensible messages, in situations where the chosen medium of communication is no one's native language.

Despite the (logical) assumption that lingua franca communication is particularly susceptible to misunderstandings owing to the fact that the participants' command of the language is imperfect, there is little intersubjectivity, and, on the other hand, much divergence in speakers' linguistic imperfections (Mauranen 2006: 123), research into the use of English as the lingua franca has shown that cases of overt misunderstanding are, in fact, less common among lingua franca speakers than in native-speaker communication (Mustajoki 2017). What is more, studies of ELF in academic settings often report little occurrence of clear misunderstanding episodes, too (e.g. Björkman 2009; Mauranen 2006). This has been attributed to the strongly cooperative, collaborative and consensus-oriented character of ELF interactions (e. g. Seidlhofer 2001:14); in addition to the let-it-pass and make-it-normal principles ${ }^{1}$ described in early work by Firth $(1990,1996)$, numerous practices and procedures have been discovered to take place in ELF discourse that allow participants to achieve mutual understanding and communicate effectively (e.g. Björkman 2013; Mauranen 2012, 2006; Meierkord 1998, 2000; Kaur 2012 etc.).

A commonly employed set of such strategies is repair, an orderly organization of practices for dealing with problems in speaking, hearing and understanding the talk in conversation and other forms of talk-in-interaction (Schegloff et al. 1977; Schegloff 1997, 2000, 2002). One of the basic dimensions of these practices is who initiates repair; the organizationally relevant way of understanding this is to differentiate between repairs initiated by the speaker of the problematic talk (hereinafter also referred to as the trouble source or the repairable), and those initiated by another speaker - self-initiation and other-initiation, respectively. Previous research on repair in ELF interactions has shown, for example, that self-initiated self repair serves as a means of making one's talk more specific, explicit, and clear, and thus helps prevent misunderstanding (Kaur 2011a, 2012; Mauranen 2006). Furthermore, Mauranen (2006) in her article on the ways ELF speakers signal and prevent misunderstandings in academic talk emphasises the importance of distinguishing between retroactive (i.e. backward-looking) repair, and repair which is employed proactively, stating that while self-repair generally functions as a preventative measure, interactive repair ${ }^{2}$ (involving another speaker either initiating or performing the repair, or both) tends to occur after the recognition of a problem in communication. It is the latter kind of repair strategies that constitute the focus of the present paper, as it reports on the nature and functions of interactive repair in the process of constructing shared understanding 
in international university seminars. Author's previous research into the nature of repair in ELF academic discussions points to instances of other-repair both addressing and pre-empting problems and misunderstandings in communication, making other-initiated repair in the given settings strongly content and goaloriented. Furthermore, other-correction has been found to perform potentially face-threatening acts (e.g. unmitigated disagreement), which may suggest that less emphasis tends to be placed on face concerns than is the case elsewhere, i. e. the communicative purpose of the genre takes precedence here and having one's utterance repaired or having someone request to repair one's message represent expected actions in ELF-mediated academic discussions.

The aim of the present study, then, was to find whether interactive repair complements self-initiated self-repair in helping the participants achieve their communicative goals within academic seminars by preventing misunderstanding and communication breakdown, more specifically, the strategies discussed in the article all involve providing language support and/or feedback to one's communicative partners in negotiating both meaning and form of talk, in spite of the fact that the latter has received little attention from ELF researchers, who are in agreement that speakers tend to be content rather than form oriented in their negotiations (e.g. Firth 1996: 25). On that note, the research question also encompasses the hypothesis that ELF speakers adapt their pragmatic behaviour to different communicative settings.

\section{Data and participants}

The examined data ${ }^{3}$ comprise eight hours of transcribed audio recordings of ELF interactions taking place at the University of Ostrava in the 2015/2016 and 2016/2017 academic years. Not only was the data collected in an academic setting, the speech events are also narrowed down to seminars, which makes it different from the casual conversations that have been studied in earlier ELF research. Here, the participants have institutional communicative goals to achieve, as they jointly co-construct knowledge, exchange and negotiate ideas. Furthermore, the seminar is a hybrid genre which denotes a number of different events and combines several rhetorical forms and modes and structures of discourse ranging from monologic presentation to multiparty discussion, depending on the discipline. The disciplinary domains represented in the corpus for this study are economics, biology, pedagogy and adult education, and sociology. In line with the principles of conversation analysis, the recordings were made by the researcher personally, and in order to ensure the naturalness of the data, they were to be made as and when the interactions happened at the locations where they would have occurred regardless of whether they were being recorded or not. The audio data was then transcribed manually using a slightly adapted version of the notation system developed by Gail Jefferson for CA (see Appendix 1 for transcription conventions). 
The participants, numbering 44 in total, come from twelve different linguacultural backgrounds ${ }^{4}$ and comprise senior university staff members and post-doc research fellows and postgraduate as well as undergraduate students. As expected in a lingua franca setting, the participants spoke different varieties of English with varying levels of proficiency; while some of the undergraduate students displayed intermediate to lower intermediate degree of command of English, the teaching staff and research students generally seemed highly proficient ${ }^{5}$. For ethical reasons, written consent was obtained from all the participants concerned prior to the data collection, and names were omitted from the transcripts in order to ensure anonymity, instead, the individual speakers are marked SX $(\mathrm{X}=$ number referring to the order in which they appear in the recordings).

\section{Methodology}

Besides numerous approaches to discourse analysis, including corpus methods, recent research into ELF has witnessed increased interest in Conversation Analysis (henceforth CA), as it requires thorough description and analysis of the sequencing of action and organization of turns at the micro level of verbal and non-verbal acts. Based on this and the fact that repair organization constitutes one of the fundamental areas of interest in CA, the choice of conversation analytic procedures as the methodological framework for the present study seems natural. It has been argued that other-repair is "quite rare" in conversation (Levinson 1983: 341), however, it must be noted that the institutional context of a university seminar as a representative of classroom talk departs from the context of ordinary conversation in a number of ways, and that it is vital to refer to this when trying to illuminate the role of repair practices in academic talk. Drew and Heritage (1992: 21-25) elaborate the departure of classroom interaction from everyday conversation as follows:

- institutional talk is goal oriented in institutionally relevant ways (the participants come to the seminar expecting exchange of scientific knowledge);

- it often involves "special and particular constraints" on "allowable contributions to the business at hand" (in seminars, as opposed to, for example, lectures, all the people present are expected to participate in the ongoing discussion);

- it may be "associated with inferential frameworks and procedures that are peculiar to specific institutional contexts".

In line with McHoul's (1990) finding that, in classrooms, other-initiation and other-repair may be expected to appear more frequently than in ordinary talk, the analysis showed that there are numerous uses of it in our data; consequently, the episodes of repair discussed in the present article involve either the 'self' or the 'other' performing the repair, and include cases of both self- and other-initiations, 
i.e. instances of self-initiated self-repair were excluded from the analysis. Selfinitiations here occur exclusively within the same turns as the trouble sources, and use non-lexical speech perturbations (cut-offs, sound stretches, hesitations markers etc.) to "signal the possibility of repair-initiation immediately following" (Schegloff et al. 1977: 367). The practices of other-initiation of repair explicitly locate the source of trouble in a prior turn (e.g. by pointing out a specific word). In compliance with the principles of CA, all the incidents were identified on the grounds of the participants' own orientations which are discernible in the details of the talk.

All the episodes were first categorised according to what source of trouble was indicated by the repair initiation, that is, hearing, understanding or acceptability. ${ }^{6}$ By acceptability we mean not only linguistic problems, but also saying something wrong in a wide sense, that is, untrue, inappropriate, or irrelevant (Svennevig 2008: 339). Furthermore, in the case of other-initiated repair, attention was also paid to how specific the repair initiations were in indicating the nature of the trouble, namely whether they employed unspecific problem indicators, category specific indicators, or candidate solutions. The classification of formats of otherinitiated repair was adopted from Svennevig's article on other-initiated repair (2008). It employs the concept of natural ordering of other-initiations of repair based on their capacity to locate a repairable (Schegloff et al. 1977: 369). Svennevig (2008: 340) offers the following illustration of such two-way classification according to the source of trouble and the method of problem management, drawing on examples from Clark \& Schaefer (1987), Mazeland (1986), Schegloff et al. (1977), and Schegloff (2007):

Table 1. The relation between sources of trouble and formats of other-initiated repair

\begin{tabular}{|l|l|l|l|}
\hline & \multicolumn{1}{|c|}{ Hearing } & \multicolumn{1}{c|}{ Understanding } & \multicolumn{1}{c|}{ Acceptability } \\
\hline $\begin{array}{l}\text { Unspecific } \\
\text { problem } \\
\text { indicators }\end{array}$ & $\begin{array}{l}\text { e.g. display of non- } \\
\text { hearing: } \\
\text { "huh?" } \\
\text { "what did you say?" }\end{array}$ & $\begin{array}{l}\text { e.g. display of incom- } \\
\text { prehension: } \\
\text { "what do you mean?" }\end{array}$ & $\begin{array}{l}\text { e.g. error indication: } \\
\text { "there's a mistake" }\end{array}$ \\
\hline $\begin{array}{l}\text { Category } \\
\text { specific } \\
\text { indicators }\end{array}$ & $\begin{array}{l}\text { e.g. repeat with ques- } \\
\text { tion word: } \\
\text { "Ross what?" }\end{array}$ & $\begin{array}{l}\text { e.g. clarification re- } \\
\text { quest: } \\
\text { "where?" }\end{array}$ & $\begin{array}{l}\text { e.g. error specification: } \\
\text { "you said (0.5) in the } \\
\text { Oxford street" }\end{array}$ \\
$\begin{array}{l}\text { Candidate } \\
\text { solutions }\end{array}$ & $\begin{array}{l}\text { e.g. hearing check } \\
\text { (full/partial repeat): } \\
\text { "Ross and fox?" }\end{array}$ & $\begin{array}{l}\text { e.g. understanding } \\
\text { check: } \\
\text { "you mean" + para- } \\
\text { phrase? }\end{array}$ & $\begin{array}{l}\text { e.g. candidate correc- } \\
\text { tion: } \\
\text { "you mean" + correc- } \\
\text { tion. }\end{array}$ \\
\hline
\end{tabular}

The results for the present data, which served as the starting point for the qualitative analysis, are summarised in the two tables below: 
Table 2. Distribution of initiations of repair according to sources of trouble addressed

\begin{tabular}{|c|c|c|c|}
\hline Hearing & Understanding & Acceptability & Total \\
\hline 8 & 18 & 23 & $\mathbf{4 9}$ \\
\hline
\end{tabular}

Table 3. Distribution of other-initiations of repair in the data according to degrees of specificity in diagnosing the problem

\begin{tabular}{|l|c|c|c|c|}
\hline & Hearing & Understanding & Acceptability & Total \\
\hline $\begin{array}{l}\text { Unspecific } \\
\text { problem } \\
\text { indicators }\end{array}$ & 3 & 5 & 0 & 7 \\
\hline $\begin{array}{l}\text { Category } \\
\text { specific } \\
\text { indicators }\end{array}$ & 0 & 1 & 0 & 1 \\
\hline $\begin{array}{l}\text { Candidate } \\
\text { solutions }\end{array}$ & 5 & 13 & 10 & 28 \\
\hline Total & 8 & 19 & 10 & $\mathbf{3 7}$ \\
\hline
\end{tabular}

The numbers in Table 2 show that problems of understanding are addressed more often than hearing problems, and that, contrary to some previous studies of repair in native-speaker as well as ELF interactions (Svennevig 2008; Tsuchiya \& Handford 2014), in the present data the problems of acceptability are dealt with frequently. From Table 3 it seems clear that when others initiate repair of hearing, understanding and acceptability problems, there is a rather strong tendency towards presenting candidate solutions to them over merely indicating their presence or specifying their nature. This confirms the general claim that there is a preference for stronger over weaker initiators of repair in conversation (Schegloff et al. 1977: 369). On the other hand, a number of previous studies on repair in various settings have suggested that there is an ordering of initiation formats according to the kinds of trouble source, since, as observed by Pomerantz (1984), different types of problems may have different consequences for the interactants and their relationships, and speakers generally "try the least complicated and costly remedy first" (Pomerantz 1984: 156). Most importantly in relation to the character of the present research, Mazeland and Zaman-Zadeh (2004) in their study on other-initiated word-clarification repair in ELF interactions formulated the rule of "non-firstness" upon making the observation that other-initiated wordclarification repair was almost always preceded by a failed attempt at hearing repair. The numbers for the present data do not seem to reflect this tendency, however, and it was partly the goal of the qualitative analysis to discover why this may be so.

It has been suggested that determining the exact role of a repair move may constitute a rather complicated task for the researcher (e.g. Mauranen 2006), however, the microanalysis of the data revealed several distinct functions which were recurrent and will be outlined in the following parts of the text. They all 
report on situations where speakers either address difficulties with the production or recollection of a lexical item on the part of their interlocutors, or challenge their lexical choices.

\section{Collaborative co-construction of expression}

It has been observed before that ELF speakers in multiparty interactions frequently perform turn co-construction (e.g. Mauranen 2006), i.e. they "collaborate to construct or complete a turn" (Kaur 2011b: 54). The present section will describe a set of practices employed by the interactants in order to assist their partners with the production of turn-constructional units, thus allowing the original speakers to either continue or conclude the actions implemented through their turns.

\subsection{Modelling pronunciation}

As it transpires from our analysis, the phenomenon can be observed already on the phonetic and phonological levels of interaction and involves co-construction of single lexical items. Kaur in her article on language repair among ELF speakers (Kaur 2011b) describes cases where speakers correct each other's pronunciation upon overt display of trouble. Episodes of this sort have been found in our data, only here instead of correcting their partners' pronunciation, speakers seem to be assisting them with the production of words which they have in their lexical inventories but fail to utilise when the situation calls for it, as the words are vital for conveying their ideas. In Excerpt 1 below, S5 shows trouble in articulating the word 'virophage':

\section{Excerpt 1}

S5: $\quad$ yeah but it's just- the signal is not for this- let's say it's not for the cell it's for the erm the- this erm other virus yeah i think it's- it's like- $i$ think the-

$\begin{array}{ll}\mathrm{S} 3: \quad \rightarrow \quad & \text { just that viro- } \mathrm{er}:: \mathrm{m}= \\ =\text { virophage }=\end{array}$

S5: $\quad=$ yeah (.) it's just use the cell yeah and i don't think it's about behaviour of this cell /.../

(KBE/LAB21D16)

The trouble takes the form of a failed attempt to pronounce the word 'virophage' and contains a series of false starts and cut offs as well as a hesitation marker following the attempt, all pointing to S5's uncertainty of the correct pronunciation and making a direct appeal for assistance. This prompts $\mathrm{S} 3$ to do repair by means of modelling the pronunciation of the word, which is latched into S5's turn, that is, produced without any perceptible pause, and instead of a move to seize the floor indicates S3's collaborative effort to assist their communicative 
partner, who is facing a phonetic challenge. The supplied solution is immediately accepted by an acknowledgement token "yeah" and, although he does not repeat the expression in question, S5 is enabled to continue his talk and the discourse can proceed smoothly. The ELF interlocutor does not correct the speaker's pronunciation; rather they provide their communicative partner with the means necessary to convey their ideas successfully.

\subsection{Supplying lexical items}

This subcategory of repair has been found and described in detail in previous research as it constitutes one of the typical characteristics of ELF spoken discourse and is not limited to academic settings (Meierkord 1998, 2000; Kaur 2011b). Although in the present analysis it also involves language assistance by means of providing a partner with a single lexical item, it differs from the previous kind of repair in that here the speakers do not display difficulty with the production of a particular expression, but they either do not have it in their vocabulary, cannot recall it (and thus, again, utilise it at the time of need) or seem to be concerned about its acceptability in the given context and are, therefore, reluctant to use it. What is important to note here is the speakers' orientation to both form and meaning of the interaction, as demonstrated by the excerpt below. S6 struggles to recall the word 'combinations' - the trouble on his part is clearly marked by the repetition of the preposition 'of' and the subsequent short pause. S8, who has been following the speaker's talk and train of thought and is equipped with the expression required to complete the utterance, collaboratively jumps in and offers the missing noun. S6 immediately accepts the proposed solution and gets on with their talk (until interrupted by S5).

\section{Excerpt 2}

S6:

$\begin{array}{lll}\text { S8: } \quad \rightarrow & \text { of }- \text { of }(.) \\ \text { combinations }=\end{array}$

S6: $\quad=$ of combinations (.) it's basically er a matrix-

S5: $\quad$ and why didn't they synthesize the pairs? /.../

(KBE/LAB27A16; 5)

Both the examples above evidence the highly collaborative and cooperative character of ELF interactions. Participants assist their communicative partners by providing suitable candidate solutions to the problems they display in form and meaning expression, showing attentiveness and involvement in the ongoing conversation, understanding, and support. 


\subsection{Validating lexical choices}

The last excerpt in this category of repair (below) illustrates another important aspect of lingua franca communication - how speakers take on and are assigned the role of language and professional experts in their academic interactions.

\section{Excerpt 3}

S2:

S4: so you mentioned that they have
$\mathrm{S} 1: \quad \rightarrow \rightarrow$ evidence that the malvirus can- can [enter the cell without-] [enter (.) yes] $=$

S4: $\rightarrow \quad=$ sorry?

S1: $\quad$ it is enter

S4: enter yes so- it is a good point so enter the cell probably without the giant virus but /.../

(KBE/LAB21D16; 2)

Here, we are presented with an exchange which begins similarly to the previous examples; word search on the part of S4 indicates an opportunity to initiate repair - utterance completion - in the subsequent turn, as inferred and performed by S1, however, S4 manages to recall the item just as S1 provides it, which leads to overlap and, subsequently, another repair initiation - this time an "open-class" initiator (Drew 1997) addressing a hearing problem. Interestingly, instead of "abdicating" the no longer necessary repair, S1 decides to confirm S4's right choice of vocabulary; the first time with a token agreement 'yes' within his own repair initiation turn, and then for the second time in the response to the hearing problem repair initiation by placing stress on 'is'. This could be potentially interpreted by S4 as S1 demonstrating his linguistic and/or professional authority, partly also owing to the fact that S1's conversational behaviour has had a disruptive effect on S4's turn, however, S4 instead shows appreciation and takes an active part in negotiating the suitable means of expression by repeating the word "enter" one more time once he has regained the opportunity to continue his turn, following with token confirmation 'yes' and metadiscursive 'it is a good point', which may also serve to benefit the other participants, who may not have been able to follow the exchange for linguistic reasons as well as lack of experience with the subject matter (both S4 and S1 are members of senior teaching staff).

\section{Addressing others' lexical choices}

While the excerpts examined above dealt with other-repair following displays of trouble on the part of the speaker, i.e. self-initiated, the next section will take a closer look at instances where repair is initiated by others based on a variety of motives, however, generally showing participants perceiving the word choices 
of their partners as less than acceptable, since the outcome of such initiations is always the replacement of an expression with a more suitable one.

\subsection{Repeats}

The first category discovered during the analysis is the practice of repeating (part of) a previous turn in prompting the speaker to use a different expression, i.e. self-reformulate. It has already been mentioned that there seems to be a preference for the use of strong repair initiators over weaker ones. What is more, it has been argued that speakers sometimes tend to address problems of acceptability by introducing repair of hearing or understanding first as they are potentially less face-threatening (Schegloff 2007: 151). Both these tendencies were observed in the present research, the latter is illustrated in the extract below:

\section{Excerpt 4}

S1: ok so what are five positive things about czech people and now i want you to speak up.

S2: $\quad \rightarrow \quad$ they are nice

S1: $\rightarrow$ we're nice?

S2: $\quad$ welcoming i mean

S1:_ welcoming um hum (.) okgo on@@@

(KPD/MCE7A16)

In this seminar on multicultural education, the participants are discussing distinctive culture-specific features of different nations and, at one point, S1 (the lecturer) invites the students to brainstorm ideas about Czechs. S2 offers the adjective 'nice', which, however, is not found suitable by S1, perhaps because of its rather broad meaning, as becomes apparent from her acceptance of the more specific term 'welcoming'. Instead of pointing out an acceptability problem, S1 opts for a format of other-initiation commonly employed in addressing hearing and understanding problems - a full repeat with rising intonation. However, S2 presupposes an acceptability problem and reformulates her utterance, which results in a successful solution of the problem and enables the communication to progress. Interestingly, the fact that $\mathrm{S} 1$ resorts to display non-understanding, which may indicate failure or "a lack of competence of some sort" (Sacks 1992: 413) on her part, instead of drawing attention to the unsuitable choice of an expression which is too general in the given context, demonstrates her pragmatic competence she avoids being over-dominant, which is crucial for the instructor in the lingua franca setting, where non-native users of English can be prevented from participating by their awareness of insufficient English proficiency (Aguilar 2016: 337). 


\subsection{Candidate understandings}

The section above supports Mauranen's claim that minimal signals (unspecific problem indicators and minimal responses) "seem to work reasonably well with many individual lexical items" (Mauranen 2006:133). Nonetheless, in other situations, participants may resort to other strategies with the aim of making their interlocutors explicate their ideas or clarify instructions. One such situation is shown in Excerpt 5, where S10 proffers a candidate understanding of the lecturer's instruction in order to check correct interpretation.

\section{Excerpt 5}

S1: $\quad \rightarrow \quad$ so now line up by body size.

S10: $\rightarrow \quad$ like height?

S1: $\quad$ yeah (.) the tallest here and the smallest here.

(KSE/INKOM4A16; 3)

S1 in ordering the students to form a line uses the expression 'body size', which, similarly to the example above, seems as not specific enough to S10, who initiates repair by means of reformulation, using the alternative (and more specific) 'height' with rising intonation. His correct understanding is then confirmed by $\mathrm{S} 1$, who uses a token agreement 'yeah' and proceeds to explain what exactly the students are expected to do, most likely accompanying the order with non-verbal elements given the presence of deictic "here" and thereby leaving no space for misinterpretation. Many similar cases of employing understanding checks of this sort were come across in the data, all serving to clarify and make explicit the sense of what has just been said. It is worth noticing here, particularly, that by "giving account of attempted understanding" (Waring 2002: 1719), S10 shows a strongly proactive and collaborative effort; not only does he "convey recipiency" (Aguilar 2016: 339) of the lecturer's message, he also asserts his linguistic competence and assists his (possibly less competent) communicative partners in expressing their own ideas and understanding others successfully, which in the end contributes to preventing possible misunderstandings, communication breakdown and fulfilment of the seminar goals.

\subsection{Other-correction}

Schegloff, in one of his early papers on other-initiated repair, claims that when recipients of the problematic talk initiate repair, they tend to let the speaker of the repairable deal with it themselves in the ensuing action (Schegloff 1997). However, the final section of the paper will illustrate an instance of lexical replacement as performed through repair which is other-initiated and resolved within a single turn. It will also present a situation where a speaker replaces a particular lexical item used by their interlocutor in an episode of explicit language repair correction, following Jefferson's definition in which correcting someone is seen 
as producing "an item which stands as a correction of an item in another's talk" (1987:87). Svennevig (2008) in his article on the preference of the least serious construal of a problem notes, besides the overall low frequency of direct initiations of acceptability problems, that although it may be more efficient to correct someone than imply the presence of an acceptability problem, speakers avoid performing other-correction, as such moves display a deficiency in their partners' contributions and constitute face-threatening acts (also Robinson 2006, Grundy 2008). The following examples then attempt to offer an insight into why there is a strong tendency towards dealing with acceptability problems in ELF academic talk through other-correction despite its face-threatening potential. Excerpt 6 documents a situation where a lexical item is replaced by one of the participants despite the absence of a difficulty on the part of the speaker or a factual error:

Excerpt 6

S2:

the thing that they figured out erm- it is evident- it is obvious from the erm panel $\mathrm{D}$ the right most graph is that when the malvirus is present the number of giant viruses that result in the infection is lower and the amount

$\rightarrow \quad$ of cells that survive the infection-

S4: $\rightarrow \quad=$ attack

S2: $\quad=$ or the attack is bigger than when the virophage is absent.

(KBE/LAB21D16; 3)

S2 comments on the processes that take place inside an organism during an infection, however, when he mentions the word 'infection', he is interrupted by S4, who suggests using the word 'attack' instead, as she considers it as more appropriate and accurate to describe what actually goes on during the infection, i.e. the aggressive manner in which the giant viruses behaves towards the cell. Similarly to Excerpt 1 above, the interruption does not stem from S4's attempt at taking over the turn, rather, it serves here to prevent ambiguity and enhance understanding shared by all the present participants, and factual correctness. This is perceived so also by $\mathrm{S} 2$, who immediately adopts the semantically narrower and more precise term and incorporates it in the continuation of his turn.

Finally, Excerpt 7 presents a number of various strategies of lexis-related repair, which are, however, sequentially intertwined. This gives evidence of the fact that in multiparty ELF academic discussions, other-initiated repair tends to become lengthy, sequentially complicated, and structurally elaborate, and that it is often negotiated by more than two speakers - the other members of the group who perceive the possibility of a breakdown contribute to the repair.

\section{Excerpt 7}

S5: they show that they erm because of this water er::m

$\begin{array}{lll} & \rightarrow & \text { water- } \\ \text { S6: } & \rightarrow & \text { marks }\end{array}$ 
S5:

S5:

$\rightarrow \quad$ so: they really erm swi- er::m=

$\mathrm{S} 2: \rightarrow$ changed $=$

S5: $\quad \rightarrow \quad=$ changed the genome (.) yeah and then they study-

S7: $\rightarrow \quad$ switch is the right word here because they didn't make the- the original genome in this one

S5: $\quad$ yeah yeah (.) and then they already tried to go further with this minimalgenome and like looking for the pieces essential non-essential genes and /text omitted/

(KBE/LAB27A16; 1)

Here, the series of non-lexical perturbations in S5' utterances in the first and fifth lines indicate a word search in progress. Both times, the speaker is helped by other participants and accepts their suggestions, however, in the second case, he is immediately corrected by another participant who seems to find the solution less than suitable and makes a move to provide an alternative, one that the Speaker was, in fact, originally about to use. By doing this, Speaker 7 performs two actions; he provides Speaker 5 with an expression that he perceives as more appropriate to describe what the speaker appears to want to convey in the given context, and, at the same time, he rejects the solution offered by S2, thus expressing an opposing view on the acceptability of the lexical item 'change'.

According to Schegloff et al. (1977), other-correction is a dispreferred next action, as compared with self-correction, and thus tends to be produced with delays (pauses, discourse markers etc.), which function as mitigating devices. Yet, as shown in the two excerpts, the interactants in the present data immediately express their corrections without using such mitigators. This kind of conversational behaviour may be present because they feel that the expressions used by the previous speakers may lead to ambiguity and misunderstanding, and thus endanger the fulfilment of their communicative goals, which prompts them to react instantly. Although the dispreferred action is not preceded by mitigation, it does not lead to communication problems for the interactants. Rather, its use is appropriate to the institutional context of the seminar in which they are participating. Speakers show their willingness to supply more suitable items to ensure mutual understanding, and the recipients also collaboratively participate in the process of meaning negotiation by showing acceptance of their solutions.

The final point of observation deals with the fact that the episodes above involve lexical replacement of items which are not necessarily inappropriate in the given contexts, instead, they tend to demonstrate a tendency of replacing the "rather general" with the "more specific" ('infection' $\rightarrow$ 'attack'; 'change' $\rightarrow$ 'switch'), that is, a phenomenon more likely to be observed in native-speaker non-native speaker interaction; as proposed by Kaur (2011b: 56) "the subject of language repair is usually confined to interactions involving native and non-native speakers of a language and it is always the native speaker who is shown to be 
doing correcting". As the speakers in the given excerpts (6 and 7) did not display any significant differences in terms of proficiency (they were all fluent English speakers whose language command featured highly advanced vocabulary), we argue here that the occurrence of the phenomenon in lingua franca interaction is given by the academic setting, where terminological accuracy and precision are crucial for communicative purpose achievement, and where "academic expertise overrides specifically linguistic expertise" (Mauranen et al. 2016: 48).

\section{Conclusion}

The paper offers a contribution to our understanding of the strategies and processes that make English as a lingua franca communication possible and efficient even in complex high-stakes academic settings, where the users have to cope with a number of complications caused by issues of proficiency, cultural differences, institutional communicative goals and pragmatic issues connected with the discourse of seminars. The present investigation of interactive repair in ELF academic interactions reveals that participants resort to this form of repair practices when assisting their communicative partners in conveying their ideas and expressing meaning where there are signs of trouble on the part of the speakers. By providing language support, they help them to overcome the challenges brought about by varying degrees of proficiency, which demonstrates their ability to follow and closely monitor the development of communication as well as willingness to intervene and offer assistance in order to ensure its successful outcome. Nonetheless, the findings also show that interactants address lexical choices of other speakers despite the absence of such difficulties and confirm our initial hypothesis that, like self-repair, interactive repair has a strongly proactive character and serves to pre-empt ambiguity, misunderstanding and communication breakdown. Furthermore, while previous research has expressed concerns about ELF users' lack of pragmatic competence (e.g. House 2002, 2013), the present paper portrays ELF speakers as competent communicators adaptable to different sociopragmatic contexts, and confirms the previously expressed notion that the effectiveness of a speaker of English in academic ELF settings is determined primarily by their pragmatic ability and less by the proficiency (Björkman 2010). The analysis revealed, for example, that lecturers pay attention to face work in communication with less linguistically and professionally competent speakers, as they apply strategies in meaning and form negotiation which have a supportive character, bearing in mind that any embarrassment arising from directly pointing out acceptability problems could hamper speakers' participation. At the same time, the recipients demonstrate their ability to interpret the underlying pragmatic motives correctly and respond to the strategies appropriately. In other situations, however, the communicative purpose seems to override pragmatic concerns when speakers employ potentially face-threatening behaviour in the form of explicit correction when ensuring accuracy of the terms used. Moreover, other- 
correction is often done in turn-disruptive manner, which in itself also increases the risk of pragmatic failure. Although it might be the case that in less formal and goal-oriented settings, ELF speakers tend to allow for various imprecise or vague formulations to pass without being commented on, in the academic setting, the primary goal of the interactants is not to get the message across with little or no emphasis on the form of delivery, instead, attention is paid to the slightest differences in meaning when referring to the subject matter discussed. The fact that the recipients in such situations generally accept and even appreciate their partners' contributions points to the possibility that ELF speakers' orientations are different in academic contexts than may be the case elsewhere (e.g. casual conversation), and goal-oriented academic interactions might emerge as alternative settings for sociopragmatic norms construction in the use of English as a lingua franca.

\section{Notes}

1 The let-it-pass and make-it-normal principles were described as methods of interactional and discursive work in ELF talk which serve to achieve ordinariness in the face of others' deviant linguistic behaviour. The let-it-pass procedure tends to be adopted in the interpretation of speakers' utterances which may pose understanding problems; instead of addressing the unknown or unclear words or utterances, the hearers assume that they will become clear or redundant as talk progresses (Firth 1996: 243). The make-it-normal principle then refers to a set of various active strategies used to divert attention from linguistically 'abnormal' forms of others' talk and indicate understanding of or agreement with the message content (Firth 1996: 245).

2 The term was borrowed from Anna Mauranen's article on misunderstandings in English as a lingua franca communication (2006).

3 The data were collected for the author's doctoral research on the subject of repair in ELF academic talk.

$4 \quad$ Overview of participants' lingua-cultural backgrounds: Czech (19), Russian (8), Polish (5), Portuguese (3), Ukrainian (2), Turkish (1), Slovak (1), German (1), Kazakh (1), Kyrgyz (1), Finnish (1), Greek (1).

5 It must be noted here that the participants were not tested for proficiency level and this is a general observation made by the researcher during the recording sessions. An anonymous reviewer suggests that the undergraduate students' limited command of English would lead to them being involved in instances of candidate solutions of acceptability (i.e. they would often be helped or corrected); however, such tendency was not observed in the analysed data. One of the reasons is presented in the discussion of Excerpt 4 (section 5.1 on repeats), where the teacher implies an understanding problem with (part of) the undergraduate student's turn, while in fact addressing an acceptability problem, and "providing place in the very next turn in which the prior speaker can make some adjustment in what was said - to make it more accessible, and perhaps more acceptable" (Schegloff 2007:151). Interestingly, Excerpts 6 and 7 illustrating other-correction involve fairly proficient speakers (also, in both cases the speakers are either research students or staff members).

6 It is important to note here that conversation analysis works with what is presented as the nature of the problem, as the analyst has not got access to its actual cause. 


\section{Acknowledgements}

This article is an output of the internal grant project SGS10/FF/2017 Communicating Across Cultures: Local and Translocal Features of Genres in Online and Offline Environment at the University of Ostrava, Czech Republic. The author would like to thank the anonymous reviewers for their insightful comments and suggestions towards improving the manuscript.

\section{References}

Aguilar, Marta (2016) Seminars. In: Hyland, Ken and Philip Shaw (eds.) The Routledge Handbook of English for Academic Purposes. London and New York: Routledge, 335-347.

Björkman, Beyza (2013) English as an Academic Lingua Franca: An Investigation of Form and Communicative Effectiveness. Berlin and New York: De Gruyter Mouton.

Björkman, Beyza (2010) So you think you can ELF: English as a lingua franca as the medium of instruction. Hermes 45, 77-99.

Björkman, Beyza (2009) From code to discourse in spoken ELF. In: Mauranen, Anna and Elina Ranta (eds.) English as a Lingua Franca: Studies and Findings. Newcastle, UK: Cambridge Scholars Press, 225-251.

Clark, Herbert H. and Edward F. Schaefer (1987) Collaborating on contributions to conversations. Language and Cognitive Processes 2, 19-41.

Drew, Paul (1997) Open class repair initiators in response to sequential sources of troubles in conversation. In: Journal of Pragmatics 28, 69-101.

Drew, Paul and John Heritage (1992) Analyzing talk at work: an introduction. In: Drew, Paul and John Heritage (eds.) Talk at Work: Interaction in Institutional Settings. Cambridge: Cambridge University Press, 3-65.

Firth, Alan (1996) The discursive accomplishment of normality: On 'lingua franca' English and conversation analysis. Journal of Pragmatics 26, 237-259.

Firth, Alan (1990) Lingua franca negotiations: Towards an interactional approach. World Englishes 9 (3), 269-280.

Grundy, Peter (2008) Doing Pragmatics. London: Hodder Education.

House, Juliane (2013) Developing pragmatic competence in English as a lingua franca. Journal of Pragmatics 59, 57-67.

House, Juliane (2002) Communicating in English as a lingua franca. EUROSLA Yearbook 2 (1), 243-261.

Jefferson, Gail (1987) On exposed and embedded correction in conversation. In: Button, Graham and John R. E. Lee (eds.) Talk and Social Organisation. Clevedon, UK: Multilingual Matters, 86-100.

Kaur, Jagdish (2011a) Raising explicitness through self-repair in English as a lingua franca. Journal of Pragmatics 43, 2704-2715.

Kaur, Jagdish (2011b) Doing being a language expert: the case of the ELF speaker. In: Archibald, Alasdair, Cogo, Alessia and Jennifer Jenkins (eds.) Latest Trends in ELF Research. Newcastle upon Tyne: Cambridge Scholars Publishing, 53-76.

Kaur, Jagdish (2012) Saying it again: Enhancing clarity in English as a lingua franca (ELF) talk through self-repetition. Text and Talk 32 (5), 593-613.

Levinson, Stephen C. (1983) Pragmatics. Cambridge: Cambridge University Press.

Mauranen, Ana, Hynninen, Nina and Elina Ranta (2016) English as the academic lingua franca. In: Hyland, Ken and Philip Shaw (eds.) The Routledge Handbook of English for Academic Purposes. London and New York: Routledge, 44-55. 
Mauranen, Anna (2012) Exploring ELF: Academic English Shaped by Non-native Speakers. Cambridge: Cambridge University Press.

Mauranen, Anna (2006) Signaling and preventing misunderstanding in English as lingua franca communication. International Journal of the Sociology of Language 177, 123-150.

Mazeland, Harrie and Minna Zaman-Zadeh (2004) The logic of clarification: some observations about word-clarification repairs in Finnish-as-a-lingua-franca interactions. In: Gardner, Rod and Johannes Wagner (eds.) Second Language Conversations. New York: Continuum, 132-156.

Mazeland, Harrie (1986) Repair-organisatie in onderwijs-interakties. In: Scholtens, Anneke and Dick Springorum (eds.) Gespreksanalyse. Universiteit Nijmegen: Instituut Nederlands, 233-246.

McHoul, Alec W. (1990) The organization of repair in classroom talk. Language in Society 19 (3), 349-377.

Meierkord, Christiane (2000) Interpreting successful lingua franca interaction. An analysis of nonnative/non-native small talk conversations in English. Linguistik Online 5 (1). Accessed on 12 August 2017, <http://linguistik-online.com>.

Meierkord, Christiane (1998) Lingua franca English: Characteristics of successful non-native/nonnative speaker discourse. Erfurt Electronic Studies in English 98 (7). Accessed on 12 August 2017, <http://webdoc.sub.gwdg.de/edoc/ia/eese/eese.html>.

Mustajoki, Arto (2017) Why is miscommunication more common in everyday life than lingua franca conversation. In: Kecskes, Istvan and Stavros Assimakopoulos (eds.) Current Issues in Intercultural Pragmatics. Amsterdam: John Benjamins Publishing Company, 55-74.

Pomerantz, Anita M. (1984) Pursuing a response. In: Atkinson, Paul and John Heritage (eds.) Structures of Social Action: Studies in Conversation Analysis. Cambridge: Cambridge University Press, $152-163$.

Robinson, Jeffrey (2006) Managing trouble responsibility and relationships during conversational repair. Communication Monographs 73 (2), 137-161.

Sacks, Harvey (1992) Lectures on Conversation. Oxford: Basil Blackwell.

Schegloff, Emanuel A. (2007) Sequence Organization in Interaction: A Primer in Conversation Analysis 1. Cambridge: Cambridge University Press.

Schegloff, Emanuel A. (2002) When 'others' initiate repair. Applied Linguistics 21 (2), 205-243.

Schegloff, Emanuel A. (2000) Overlapping talk and the organization of turn-taking for conversation. Language and Society 29, 1-63.

Schegloff, Emanuel A. (1997) Practices and actions: Boundary cases of other-initiated repair. Discourse Processes 23 (3), 499-545.

Schegloff, Emanuel A., Jefferson, Gail and Harvey Sacks (1977) The preference for self-correction in the organization of repair in conversation. Language 53 (2), 361-382.

Seidlhofer, Barbara (2001) Closing a conceptual gap: The case for a description of English as a lingua franca. International Journal of Applied Linguistics 11 (2), 133-158.

Svennevig, Jan (2008) Trying the easiest solution first in other-initiated repair. Journal of Pragmatics 40 (2), 333-348.

Tsuchiya, Keiko and Michael Handford (2014) A corpus-driven analysis of repair in a professional ELF meeting: Not 'letting it pass'. Journal of Pragmatics 64, 117-131.

Waring, Hansun Z. (2002) Expressing noncomprehension in a US graduate seminar. Journal of Pragmatics 34, 1711-1731.

\section{Appendix 1 - Transcription conventions}

The transcription is broad, that is, minor pronunciation deviations are not included in the article because they are not vital for the demonstration of the phenomena. The speakers in each extract have been labelled as S1, S2, etc., in the order in which they appear in the recording. 
(.) pause of up to five seconds

(...) pause longer than five seconds

(a) beat of laughter

[ ] overlapping speech

(xxx) speech unintelligible

(text) approximate transcription

: $\quad$ stretched vowel

. falling intonation

? rising intonation

/.../ speech omitted from the example

bold used here to highlight parts of the extract which are discussed in the text

- false start/cut off/interrupted speech

$=$ latching

$\rightarrow \quad$ to indicate trouble source line

$\rightarrow \quad$ to indicate repair proper line

(NAME) participant's name omitted

Magdalena Hanusková studied English Language and Literature and English for Translation at the Faculty of Arts of the University of Ostrava, where she is currently pursuing $\mathrm{PhD}$ studies in the English language. In her research she deals with spoken academic discourse and the use of English as a lingua franca in academic contexts. She teaches linguistic courses at the Department of English and American Studies (University of Ostrava) as well as ESP courses at the Faculty of Science and the Faculty of Social Studies. Having nine years of experience in teaching English as a foreign language, she is now a certified examiner for Cambridge English Language Assessment, supplies methodological work to private educational institutions and teaches didactics in courses for pedagogical workers. She is an active translator and interpreter from and into English.

Address: Mgr. Magdalena Hanusková, Department of English and American Studies, Faculty of Arts, University of Ostrava, Reální 1476/5, 70200 Ostrava, Czech Republic. [Magdalena.Hanuskova@osu.cz] 